\title{
Updated Guidelines for the Management of Axial Disease in Psoriatic Arthritis
}

\author{
Peter Nash, Ennio Lubrano, Alberto Cauli, William J. Taylor, Ignazio Olivieri, \\ and Dafna D. Gladman
}

\begin{abstract}
Axial involvement in patients with psoriatic arthritis (PsA) remains common and can be defined in terms of spinal disease alone or in combination with peripheral manifestations. Diagnosis is based upon inflammatory spinal symptoms or the presence of radiological sacroiliitis and other radiographic signs of spondylitis, or by criteria for axial spondyloarthritis (SpA) defined by ASAS (Assessment of SpondyloArthritis International Society). Although recent data are scarce for efficacy of traditional therapies for axial disease (e.g., nonsteroidal antiinflammatory drugs, methotrexate, etc.), limited data are available for targeted biologics and novel agents. We identify and evaluate the efficacy of therapeutic interventions for treatment of axial disease in PsA. This review is an update of the axial PsA section of the treatment recommendations project by the Group for Research and Assessment of Psoriasis and Psoriatic Arthritis (GRAPPA). (J Rheumatol 2014;41:2286-9; doi:10.3899/jrheum.140877)
\end{abstract}

Key Indexing Terms:

PSORIATIC ARTHRITIS SPONDYLOARTHRITIS TXIAL THERAPY

Despite shared features with ankylosing spondylitis (AS), important distinctions in patients with axial psoriatic arthritis (axPsA) include reduced male preponderance; less overall spinal disease severity; asymmetric and less severe sacroiliitis; "spotty" asymmetric distribution of marginal and paramarginal syndesmophytes with random progression, better preservation of spinal mobility; relative sparing of apophyseal joints; frequent involvement of cervical spine; and reduced association with the HLA-B*27 allele ${ }^{1,2,3}$. However, although recent data confirm these observations, no differences were found in the effect of axPsA on functional capacity, disease activity, and quality of life, compared to $\mathrm{AS}^{4}$.

From the Department of Medicine, University of Queensland, Australia; Academic Rheumatology Unit, Department of Medicine and Health

Sciences, University of Molise, Campobasso, Italy; Rheumatology Unit, Department of Medical Sciences, University of Cagliari, Cagliari, Italy; Rehabilitation Teaching and Research Unit, University of Otago, Wellington, New Zealand; Rheumatology Department of Lucania, San Carlo Hospital of Potenza and Madonna delle Grazie Hospital of Matera, Italy; and University of Toronto and Toronto Western Research Institute, Toronto, Ontario, Canada.

P. Nash, MBBS (Hons), FRACP, Department of Medicine, University of Queensland; E. Lubrano, MD, PhD, Academic Rheumatology Unit, Department of Medicine and Health Sciences, University of Molise; A. Cauli, MD, PhD, Rheumatology Unit, Department of Medical Sciences, University of Cagliari; W.J. Taylor, MBChB, PhD, FRACP,

Rehabilitation Teaching and Research Unit, University of Otago; I. Olivieri, MD, Rheumatology Department of Lucania, San Carlo Hospital of Potenza and Madonna delle Grazie Hospital of Matera; D.D. Gladman, MD, FRCPC, Professor of Medicine, University of Toronto, Senior Scientist, Toronto Western Research Institute.

Address correspondence to Dr. P. Nash, Department of Medicine, University of Queensland, PO Box 308, Maroochydore, Australia. E-mail:drpnash@tpg.com.au
Treatments for axial disease in PsA have not been specifically studied, because no formal effort has been undertaken to identify this patient subset. Small numbers of patients in PsA trials have defined "spondylitis," and equally small numbers of patients in AS trials have psoriasis. In the absence of adequate studies in patients with axPsA, criteria and outcome measures developed for AS have been accepted by consensus for use in axPsA, and response to therapy assumed to be equivalent between AS and axPsA. This view is supported by 2 recent studies comparing axPsA and AS that confirmed no differences as far as effect on functional capacity, disease activity, and quality of life ${ }^{5}$. However, in a prospective cohort study of 201 patients with axPsA, the Bath AS Disease Activity Index (BASDAI) showed only good to moderate ability to discriminate between high and low disease activity, and no significant superiority over the AS Disease Activity Score (ASDAS). Moreover, sensitivity to change and minimal clinically significant differences have not been demonstrated ${ }^{6}$.

This systematic review is an update of one published with GRAPPA collaboration in $2006^{5}$. We set out to answer the following questions: What published graded evidence is available to guide therapy for axPsA? Given the paucity of clinical trial data for axPsA, what evidence base exists for therapy in AS?

The literature of Medline, Embase, CINAHL, and the Cochrane Library from 2006 to March 2014 was searched using the key words [MeSH (US National Library of Medicine Medical Subject Headings)] "Ankylosing Spondylitis (AS)," "Psoriatic Arthritis (PsA)," "AS and PsA," "PsA and axial disease," "spondylarthropathy (SpA) and 
psoriasis," "spondylitis and psoriasis," "anti-rheumatic therapy," as well as combinations of the following key words with PsA: spondylarthropathy or spondylitis: salazopyrine, methotrexate (MTX), physiotherapy, pamidronate, gold oral and intramuscular, azathioprine, cyclosporine, hydroxychloroquine, infliximab, etanercept, adalimumab, and tumor necrosis factor (TNF), apremilast, ustekinumab, tocilizumab, secukinumab, brodalumab, rituximab, and abatacept.

Articles were selected that specifically addressed axial disease and its therapy in psoriasis, PsA, AS, or SpA. In addition, abstracts were extracted from annual meetings of the American College of Rheumatology and the European League Against Rheumatism from 2006 to 2014. Abstracts were admitted only if sufficient detail was available to determine level of evidence.

Evidence extracted from the published literature and/or from expert opinion was graded according to the recommendations of AHCPR 1994 as defined in previous $\operatorname{articles}^{5}$.

Satisfactory treatment for axPsA should aim to relieve signs and symptoms (i.e., pain, stiffness, and restriction in spinal mobility); improve physical functioning and quality of life; inhibit progression of structural damage; and prevent disability. Although outcome measures in axPsA are under active assessment and require formal validation, the ASAS Working Group has developed response criteria for improvement in AS; by consensus these were used in this review ${ }^{7}$. ASAS-validated composite measures assess disease activity (BASDAI), function (Bath AS Functional Index), patient global (Bath AS Global Index), and spinal mobility (Bath AS Metrology Index). Structural damage is evaluated using validated radiographic instruments [Bath AS Radiology Index/modified Stoke AS Spine Score (BASRI/mSASSS)]. The recently defined Psoriatic Arthritis Spondylitis Radiology Index needs further validation $^{8,9}$.

\section{Results in Previous GRAPPA Review}

No new studies have been published since the 2006 GRAPPA article on the following specific therapies for axPsA: physiotherapy, simple analgesia, nonsteroidal antiinflammatory drugs (NSAID), corticosteroids, sulfasalazine, thalidomide, auranofin, cyclosporine, leflunomide, MTX, anakinra, and bisphosphonates ${ }^{5}$.

\section{Results Specific to This Review}

NSAID. Two studies in AS have suggested that continuous NSAID therapy could retard radiographic progression in $\mathrm{AS}^{10,11}$. This has not been examined in axPsA.

Methotrexate. Although no new data are available, the Methotrexate in Psoriatic Arthritis (MIPA) study ${ }^{12}$ was unable to show significant superiority of MTX compared to placebo in PsA; however, no attempt was made to analyze efficacy in axPsA.

\section{Targeted Biologic Therapies}

Anti-TNF therapy. In AS, psoriasis, and PsA, Level A evidence is available for significant benefit with etanercept, infliximab, adalimumab, certolizumab pegol, and golimumab on disease activity, range of motion, physical function, and quality of life, both as monotherapy and as add-on therapy to other disease modifying antirheumatic drugs (DMARD). Radiological progression was retarded in PsA with etanercept, adalimumab, certolizumab, golimumab, and infliximab ${ }^{13,14,15,16,17}$. Significant response was seen with certolizumab in NSAID-refractory patients with long-standing and severe disease (RAPID-axSpA trial), and benefit was maintained out to 12 months with continued therapy (level of evidence 1 a Grade A) ${ }^{13}$. In an observational study of patients with PsA with axial manifestations, the effectiveness at 12 months of etanercept therapy was assessed per the ASAS response criteria; $72 \%$ of patients had improvement in the BASDAI, as well as in other outcome measures ${ }^{15}$.

In the golimumab PsA study ${ }^{16}$, enthesitis and dactylitis were scored, but no attempt was made to score axial disease or assess response to treatment, despite $10 \%-12 \%$ of patients having spondylitis with peripheral arthritis. In the golimumab AS study, despite $5 \%-11.4 \%$ of patients having psoriasis, no attempt was made to analyze this small cohort for response separate to the overall AS group ${ }^{18}$.

In the certolizumab, RAPID-axSpA trial, no psoriasis subset was defined ${ }^{13}$. In the adalimumab study of nonradiographic axSpA, psoriasis and PsA were exclusions ${ }^{19}$. Two studies with etanercept have shown some evidence that anti-TNF therapy may retard structural damage in $\mathrm{AS}^{20,21}$, but this is unknown in axPsA.

With the exception of infliximab, DMARD co-therapy (MTX) does not appear to improve anti-TNF survival/ retention $^{22}$.

Outstanding issues under investigation include optimal longterm maintenance dosage and schedule of administration, formal economic analysis assessing the cost-benefit of these therapies in $\mathrm{SpA}$, and prognostic factors for determining response to anti-TNF treatment.

For considerations of safety, both short- and long-term, and the effect size of therapeutic interventions, physicians should refer to ASAS recommendations.

\section{Novel Agents}

In a phase 3, 12-month study, ustekinumab [monoclonal antibody directed against the p40 subunit of interleukin 12 (IL-12) and IL-23] showed significant reduction in BASDAI 20 and 70 (but not 50) at the 45-mg dose (subcutaneous; baseline, week 4 , then every 12 weeks), and significant reduction at BASDAI 20/50/70 levels at the 90-mg dose, in addition to significant reductions in enthesitis and dactylitis (Level 1a) ${ }^{23}$.

A study of secukinumab (IL-17 inhibitor) excluded

Personal non-commercial use only. The Journal of Rheumatology Copyright (C) 2014. All rights reserved 
$\mathrm{SpA}^{24}$; however, enthesitis was not significantly improved. A placebo-controlled, phase 2, 12-week study of subcutaneous brodalumab, an IL-17A receptor antibody, showed BASDAI was significantly improved at the $280-\mathrm{mg}$ dose but not 140-mg dose, nor were there improvements in enthesitis and dactylitis ${ }^{25}$.

Tocilizumab and sarilumab (IL-6 inhibitors), abatacept ( $\mathrm{T}$ cell costimulation inhibitor), and rituximab (CD20 inhibitor) have failed to show efficacy in AS and have not been formally tested in axPsA ${ }^{26,27,28,29}$. In the PALACE studies of apremilast (phosphodiesterase type 4 inhibitor), PsA patients were analyzed for dactylitis and enthesitis but not axial disease ${ }^{30}$. JAKinase inhibitors are presently under study.

We suggest that the 2010 updated ASAS specifications and definitions for diagnosis, assessment of disease, treatment failure, treatment contraindications, and assessment of response be applied to study axPsA until more formal studies are performed in this subset and validated outcome measures are developed for this domain ${ }^{7}$.

\section{REFERENCES}

1. Hanly JG, Russell ML, Gladman DD. Psoriatic spondyloarthropathy: A long term prospective study. Ann Rheum Dis 1988;47:386-93.

2. Scarpa R, Oriente P, Pucino A, Vignone L, Cosentini E, Minerva A, et al. The clinical spectrum of psoriatic spondylitis. Br J Rheumatol 1988;27:133-7.

3. Helliwell PS, Hickling P, Wright V. Do the radiological changes of classic ankylosing spondylitis differ from the changes found in the spondylitis associated with inflammatory bowel disease, psoriasis, and reactive arthritis? Ann Rheum Dis 1998;57:135-40.

4. Perez Alamino R, Maldonado Cocco JA, Citera G, Arturi P, Vazquez-Mellado J, Sampaio-Barros PD, et al. Differential features between primary ankylosing spondylitis and spondylitis associated with psoriasis and inflammatory bowel disease. J Rheumatol 2011;38:1656-60.

5. Nash P. Therapies for axial disease in psoriatic arthritis. A systematic review. J Rheumatol 2006;33:1431-4.

6. Eder L, Chandran V, Shen H, Cook RJ, Gladman DD. Is ASDAS better than BASDAI as a measure of disease activity in axial psoriatic arthritis? Ann Rheum Dis 2010;69:2160-4.

7. van der Heijde D, Sieper J, Maksymowych WP, Dougados M, Burgos-Vargas R, Landewe R, et al. 2010 Update of the international ASAS recommendations for the use of anti-TNF agents in patients with axial spondyloarthritis. Ann Rheum Dis 2011;70:905-8.

8. Lubrano E, Marchesoni A, Olivieri I, D'Angelo S, Spadaro A, Parsons WJ, et al. Psoriatic arthritis spondylitis radiology index: A modified index for radiologic assessment of axial involvement in psoriatic arthritis. J Rheumatol 2009;36:1006-11.

9. Lubrano E, Marchesoni A, Olivieri I, D'Angelo S, Spadaro A, Parsons WJ, et al. The radiological assessment of axial involvement in psoriatic arthritis: A validation study of the BASRI total and the modified SASSS scoring methods. Clin Exp Rheumatol 2009;27:977-80.

10. Poddubnyy D, Rudwaleit M, Haibel H, Listing J, Marker-Hermann E, Zeidler H, et al. Effect of non-steroidal anti-inflammatory drugs on radiographic spinal progression in patients with axial spondyloarthritis: Results from the German Spondyloarthritis
Inception Cohort. Ann Rheum Dis 2012;71:1616-22.

11. Haroon N, Kim TH, Inman RD. NSAIDs and radiographic progression in ankylosing spondylitis: Bagging big game with small arms? Ann Rheum Dis 2012;71:1593-5.

12. Kingsley GH, Kowalczyk A, Taylor H, Ibrahim F, Packham JC, $\mathrm{McHugh}$ NJ, et al. A randomized placebo-controlled trial of methotrexate in psoriatic arthritis. Rheumatology 2012;51:1368-77.

13. van der Heijde D, Fleischmann R, Wollenhaupt J, Deodhar A, Kielar D, Woltering F, et al. Effect of different imputation approaches on the evaluation of radiographic progression in patients with psoriatic arthritis: Results of the RAPID-PsA 24-week phase III double-blind randomised placebo-controlled study of certolizumab pegol. Ann Rheum Dis 2014;73:233-7.

14. Braun J, Rudwaleit M, Kary S, Kron M, Wong RL, Kupper H. Clinical manifestations and responsiveness to adalimumab are similar in patients with ankylosing spondylitis with and without concomitant psoriasis. Rheumatology 2010;49:1578-89.

15. Lubrano E, Spadaro A, Marchesoni A, Olivieri I, Scarpa R, D'Angelo S, et al. The effectiveness of a biologic agent on axial manifestations of psoriatic arthritis. A twelve months observational study in a group of patients treated with etanercept. Clin Exp Rheumatol 2011;29:80-4.

16. Kavanaugh A, McInnes I, Mease P, Krueger GG, Gladman D, Gomez-Reino J, et al. Golimumab, a new human tumor necrosis factor alpha antibody, administered every four weeks as a subcutaneous injection in psoriatic arthritis: Twenty-four-week efficacy and safety results of a randomized, placebo-controlled study. Arthritis Rheum 2009;60:976-86.

17. Antoni CE, Kavanaugh A, Kirkham B, Tutuncu Z, Burmester GR, Schneider U, et al. Sustained benefits of infliximab therapy for dermatologic and articular manifestations of psoriatic arthritis: Results from the Infliximab Multinational Psoriatic Arthritis Controlled Trial (IMPACT). Arthritis Rheum 2005;52:1227-36.

18. Inman RD, Davis JC Jr, van der Heijde D, Diekman L, Sieper J, Kim SI, et al. Efficacy and safety of golimumab in patients with ankylosing spondylitis: Results of a randomized, double-blind, placebo-controlled, phase III trial. Arthritis Rheum 2008;58:3402-12.

19. Sieper J, van der Heijde D, Dougados M, Mease PJ, Maksymowych WP, Brown MA, et al. Efficacy and safety of adalimumab in patients with non-radiographic axial spondyloarthritis: Results of a randomised placebo-controlled trial (ABILITY-1). Ann Rheum Dis 2013;72:815-22.

20. Mease PJ, Goffe BS, Metz J, VanderStoep A, Finck B, Burge DJ. Etanercept in the treatment of psoriatic arthritis and psoriasis: A randomised trial. Lancet 2000;356:385-90.

21. Mease PJ, Kivitz AJ, Burch FX, Siegel EL, Cohen SB, Ory P, et al. Etanercept treatment of psoriatic arthritis: Safety, efficacy, and effect on disease progression. Arthritis Rheum 2004;50:2264-72.

22. Fagerli KM, Lie E, van der Heijde D, Heiberg MS, Lexberg AS, Rodevand E, et al. The role of methotrexate co-medication in TNF-inhibitor treatment in patients with psoriatic arthritis: Results from 440 patients included in the NOR-DMARD study. Ann Rheum Dis 2014;73:132-7.

23. McInnes IB, Kavanaugh A, Gottlieb AB, Puig L, Rahman P, Ritchlin C, et al. Efficacy and safety of ustekinumab in patients with active psoriatic arthritis: 1 year results of the phase 3 , multicentre, double-blind, placebo-controlled PSUMMIT 1 trial. Lancet 2013;382:780-9.

24. McInnes IB, Sieper J, Braun J, Emery P, van der Heijde D, Isaacs JD, et al. Efficacy and safety of secukinumab, a fully human anti-interleukin-17A monoclonal antibody, in patients with moderate-to-severe psoriatic arthritis: A 24-week, randomised, double-blind, placebo-controlled, phase II proof-of-concept trial. Ann Rheum Dis 2014;73:349-56.

25. Mease PJ, Genovese MC, Greenwald MW, Ritchlin CT, Beaulieu

Personal non-commercial use only. The Journal of Rheumatology Copyright @ 2014 . All rights reserved. 
$\mathrm{AD}$, Deodhar A, et al. Brodalumab, an anti-IL17RA monoclonal antibody, in psoriatic arthritis. N Engl J Med 2014;370:2295-306.

26. Sieper J, Porter-Brown B, Thompson L. Tocilizumab (TCZ) is not effective for the treatment of ankylosing spondylitis (AS): Results of a phase 2, international, multicentre, randomised, double-blind, placebo-controlled trial [abstract]. Ann Rheum Dis 2012;71 Supp13:110.

27. Sieper J, Inman RD, Badalamenti S. Sarilumab for the treatment of ankylosing spondylitis: Results of a phase 2, randomized, double-blind, placebo-controlled, international study (ALIGN) [abstract]. Ann Rheum Dis 2012;71 Suppl3:111.
28. Song IH, Heldmann F, Rudwaleit M, Haibel H, Weiss A, Braun J, et al. Treatment of active ankylosing spondylitis with abatacept: An open-label, 24-week pilot study. Ann Rheum Dis 2011;70:1108-10.

29. Song IH, Heldmann F, Rudwaleit M, Listing J, Appel H, Braun J, et al. Different response to rituximab in tumor necrosis factor blocker-naive patients with active ankylosing spondylitis and in patients in whom tumor necrosis factor blockers have failed: A twenty-four-week clinical trial. Arthritis Rheum 2010;62:1290-7.

30. Schett G, Wollenhaupt J, Papp K, Joos R, Rodrigues JF, Vessey AR, et al. Oral apremilast in the treatment of active psoriatic arthritis: Results of a multicenter, randomized, double-blind, placebo-controlled study. Arthritis Rheum 2012;64:3156-67. 